\title{
"En la madrugada" de Juan Rulfo: una indagación sobre las causas
}

ANDREA Ostrov

Facultad de Filosofía y Letras, Universidad de Buenos Aires

La construcción de la causalidad en el texto

El viejo Esteban es condenado por haber matado a su patrón en una pelea. Sin embargo, de esto no hay evidencia alguna. Y si bien don Justo ha muerto, la causa de su muerte es incierta. De esta muerte hay dos interpretaciones posibles: Esteban pudo o no haberlo matado en la pelea. Ninguna de las voces narrativas del texto proporciona pruebas sobre ello.

El narrador - una de estas voces narrativas - relata la muerte de Justo desde el punto de vista de este personaje:

Corrí y agarró al viejo por el cuello y lo tiró contra las piedras, dándole de puntapiés y gritándole cosas de las que él nunca conoció su alcance. Después sintió que se le nublaba la cabeza y caía rebotando contra el empedrado del corral. Quiso levantarse y volvió a caer, y al tercer intento se quedó quieto. Una nublazón negra le cubrí la mirada cuando quiso abrir los ojos. No sentía dolor, sólo una cosa negra que le fue oscureciendo el pensamiento hasta la oscuridad total (62; los subrayados son míos).

En todo este pasaje no hay una sola marca linguística de causalidad. En cambio, el ensamblaje de hechos está construido sobre una serie de indicios temporales: "despues, "cuando", "hasta". Esa ausencia de marcas de causalidad sugeriría que no se postula aquí una relación de causa-efecto entre los acontecimientos narrados en 
el párrafo, sino únicamente una relación de contigüidad, de sucesión temporal. El narrador describe solamente una sucesión de hechos en el tiempo.

La causa de la muerte de Justo constituye, por lo tanto, un punto de indeterminación en el texto. En este sentido, puede decirse que los acontecimientos relatados por el narrador permanecen oscuros, como si estuvicran "rodeados de niebla". Y es justamente la niebla el elemento preponderante en el marco descriptivo constituido por el primero y último párrafos, los cuales "rodean" a los demás del cuento. La historia está, de este modo, rodeada de niebla.

Ahora bien, a lo largo del texto se va viendo claramente que ha habido una inferencia de causalidad con respecto a la muerte de Justo. Su causa ha sido construida precisamente a partir de la sucesión temporal de dos hechos: la pelea entre Esteban y Justo y la muerte del patrón. Sin embargo, esta inferencia, esta construcción causal, tiene lugar a partir de condiciones ideologicas específicas. Es evidentemente verdadero que si Esteban mató a Justo en una pelea, Esteban y Justo tuvieron cfectivamente una pelea. Por el contrario, la afirmación del asesinato como verdad absoluta únicamente a partir de la certeza de que existio un enfrentamiento entre ambos implica un razonamiento falaz. Este tipo de seudorazonamiento se llama, en términos lógicos, falacia de afirmación del consecuente. Y es esta falacia la que, operando a cara descubierta en el espacio social construido por el texto, constituye, por ser habitual, el argumento represor fundamental de la ideología dominante. $Y$ es la que, institucionalizada, crea y construye la culpa: "Desde el momento que me tienen aquí en la cárcel, por algo ha de ser, ¿no cree usted?" dice Esteban (60; los subrayados son míos).

Dos lecturas

La ambigüedad o incertidumbre que produce el pasaje de la muerte de Justo en lo que a la causalidad se refiere constituye el 
punto de arranque para dos lecturas opuestas del relato. Una primera lectura, identificada con la autoridad, con la ley que en el texto condena al personaje, reconocería culpable al viejo Esteban, utilizando como argumento la misma falacia logica en virtud de la cual el viejo es condenado en el texto. Y a partir de este isomorfismo ideologico, el texto se cierra: alguien comete supuestamente un crimen y es castigado de acuerdo con la ley vigente. Tal circuito es reproducido exactamente por esta primera lectura.

Sin embargo, es posible construir una segunda lectura, no identificada con esa ley sino opuesta a ella, que obedecería a condiciones ideológicas de producción diferentes y que por lo tanto pondría en juego otras asociaciones, otras relaciones entre los acontecimientos narrados. De acuerdo con esa segunda lectura -que no se haría eco de la falacia dominante, sino que, por el contrario, asumiría los silencios narrativos como puntos álgidos, como momentos textuales propicios para deslizamientos ideológicos- la condena del viejo Esteban aparecería claramente como infundada e injusta.

Ante semejante impugnación de la condena, cabría preguntarse si más allá de la culpa aparente construida en la primera lectura existe otra culpa, otra causa que "justifique" o explique la condena que se ejerce sobre el viejo; si más allá de la legalidad fundada en un crimen (hipotético), el texto funda una legalidad más sutil, menos aparente, pero más verdadera, en cuanto que comprendería razones vinculadas a momentos fundamentales, estructurales, de un sistema jurídico.

\section{La voz excluida}

La voz de Esteban, la otra voz narrativa del texto, aparece absolutamente determinada por el lugar de su enunciación: la cárcel. No puede, por eso, excluir de su discurso la supuesta causa de su condena, si bien esa causa aparece relativizada por su ausencia de memoria al respecto. En efecto, a pesar de recordar en riguroso 
orden cronológico todos los hechos sucedidos, no recuerda haber matado a Justo. Y a pesar de que hace prevalecer en su discurso la "objetividad" de la ley por sobre la subjetividad de sus recuerdos - "Pero desde el momento que me tienen aquí en la cárcel, por algo ha de ser, ¿no cree usted?" (60)_, el hecho de que no se acuerde del crimen opera como velado cuestionamiento de la construcción de la causalidad en virtud de la cual es condenado: “¿No cree usted que matar a un prójimo deja rastros?” (60).

El cuestionamiento de la ley tiene un correlato especular en otro nivel textual. Puesto que el tiempo de enunciación de Esteban es posterior al tiempo de enunciación del narrador, los párrafos hablados por el personaje aparecen como "incrustados" en el discurso del narrador en tercera persona. Esteban rompe, de este modo, el orden cronológico absolutamente lineal del discurso de aquél. Y si prescindimos en la lectura de los párrafos de Esteban, la narración no sólo reencuentra su linealidad perfecta, sino que se presenta además como relato circular: comienza y termina con descripciones similares del amanecer. Circularidad, composición en anillo que emparienta al relato del narrador con la tradición -con la ley- literaria clásica: los relatos homéricos.

Por otro lado, esa misma circularidad convertida en ley es precisamente el movimiento que el personaje se ve obligado a reproducir, a obedecer, con las vacas:

Si me la pasaba en un puro viaje con las vacas: las llevaba a Jiquilpan, donde él había comprado un potrero de pasturas; esperaba a que comieran y luego me las traía de vuelta para llegar con ellas de madrugada. Aquello parecía una eterna peregrinación (63).

Esteban rompe, entonces, mediante su imupción narrativa, la cronología lineal, el orden establecido para la narración. A partir de eso sería lícito indagar si existe en la historia narrada algún elemento que funcione como correlato factual de la ruptura formal del "orden". 


\section{Lo no narrado}

A la vez que formalmente rompe el orden de la narración en tercera persona, el discurso de Esteban desafía también en otro aspecto al discurso del narrador. Éste adopta, por un lado, características omniscientes, al narrar, por ejemplo, la muerte de Justo. Pero, por otro lado, realiza una selección muy particular de los hechos que introduce en su relato. Y es precisamente el parlamento de Esteban el que exhibe, por constraste, las omisiones en que incurre el narrador, de tal manera que establece nuevamente una velada acusación: a partir del discurso de Esteban, el discurso del narrador se vuele "culpable" de omisión.

Uno de los hechos significativamente excluidos del relato por el narrador es la condena de Esteban. De ésta nos enteramos únicamente a través de los párrafos en que habla el personaje. Pero también excluye, llamativamente, los acontecimientos que aprendemos de Esteban en el tercer párrafo:

1) "Llegué al zaguán del corral y no me abrieron" (59; el subrayado es mío).

2) "Se quebró la piedra con la que estuve tocando la puerta y nadie salió" (59).

3) "Busqué dónde estuviera bajita la barda y por allí me trepé y caí al otro lado" (59; el subrayado es mío).

4) "Vi al patrón don Justo que salía de donde estaba el tapanco, con la niña Margarila dormida en sus brazos" (59).

Nada de esto es mencionado por el narrador; todos los sucesos son igualmente silenciados en su discurso. Tienen, por lo tanto, el mismo status narrativo: el del silencio. Ello permitiría suponer, entonces, la existencia de otras relaciones, de otras vinculaciones, igualmente silenciadas, entre los hechos.

¿Se trataría quizás de la relación que existe entre un delito y su condena? A partir del silencio homologador de los hechos no narrados por el discurso del narrador, ¿no sería posible postular una relación de causa-efecto entre tales acontecimientos, ya que en 
otro momento del texto se produce también, según se ha visto, un silencio del narrador que involucra, precisamente, a la relación de causalidad?

\section{La culpa y la condena}

Esteban es condenado por haber matado a Justo, delito supuestamente cometido con una piedra ("Que dizque con una piedra, ¿verdad?" (61), dice Esteban): piedra angular para suponer que, aunque no se trate del instrumento del supuesto asesinato, del delito hipotético pero explícito en los distintos discursos narrativos, se trataría de todos modos del instrumento de otro delito, de otra culpa silenciada por el narrador. El crimen cometido con esta piedra es en realidad otro. Detrás del delito aparente existe un delito oculto.

En efecto, hay una piedra, rota, por la cual es condenado el personaje. Pero con esta piedra Esteban no ha matado a Justo. Ha golpeado la puerta. ("Se quebró la piedra con la que estuve tocando la puerta" (59)). Cuando cae al otro lado de la barda, Esteban penetra, de hecho, en un espacio geográfico y social, la hacienda de Justo, que no le pertenece. Ese salto al otro lado supone la violación de un límite: la barda ("Busqué dónde estuviera bajita la barda"). Delito, si se quiere, ancestral, hybris mítica, con jurisprudencia asentada en la literatura de la antigüedad clásica: Remo, el hermano no favorecido por los auspicios, salta envidioso el límite (mundus) de la ciudad de Roma que está siendo fundada por Rómulo. Eso jústifica que sea muerto a manos de su hermano, porque el límite es considerado sagrado. Aquí también se trata de un problema de espacios y de límites; pero ya no del límite sagrado de una ciudad, sino del límite "sagrado" de la propiedad privada. Precisamente es una metafórica "violación de espacios" 10 que provoca la lucha entre Esteban y Justo: el patrón ve al viejo "metiendo sus manos" en el hocico del animal; y el animal, patrimonio privado de Justo, constituye una corporeización de su espacio. 
La verdadera culpa es, entonces, el salto al otro lado. Sin embargo, este salto tiene como condición una exclusión previa - "no me abrieron", dice el personaje-, que se inscribe en el texto precisamente mediante la mencionada exclusión del discurso de Esteban en el relato del narrador.

\section{El lugar de la enunciación}

Paradójicamente, en este espacio en el que penetra Esteban la ley es violada concreta y conscientemente: Justo comete incesto con su sobrina. El personaje mismo es, de nuevo, quien expone su delito, pero esta vez con plena conciencia: "Dirá que es un incesto y nos excomulgará a los dos", dice Justo (61-62). Sin embargo, esta falta permanece impune a lo largo del relato. En ese espacio, el espacio geográfico-social de Justo, el centro, el omphalos mundi en la isotopía mítica, se viola la ley sin que haya castigo, porque es ése, precisamente, el espacio, el lugar de la enunciación de la ley. Justo, su mismo nombre lo indica, es la ley.

Pero el viejo Esteban ha sido testigo de ese incesto. Ha visto, involuntariamente, cómo el patrón atravesaba el campo con su sobrina en brazos. Ha visto lo que nadie debía ver ("Más vale dejar las cosas en secreto" (62), dice Justo). Esteban ha visto la transgresión de la ley desde adentro mismo de la ley. Es decir, si Jüsto es la ley, Esteban ha visto cómo la ley se transgrede a sí misma. La ley aparece entonces en el texto exhibiendo su propia falibilidad, su parcialidad, mostrando su agujero negro, su grieta estructural. La ironía consiste en que, en virtud de su específico funcionamiento, esa ley que se autotransgrede convierte en transgresor, en culpable, al testigo de la autotransgresión. Y Esteban parece tener cierta conciencia de ello cuando insiste en afimmar que Justo "de seguro no me vio" (59).

Por otra parte, es precisamente el mismo delito, el incesto, pero desplazado a los animales, lo que Esteban intenta castigar cuando golpea al becerro en el mismo párrafo: "Estás ya por parir y te 
encariñas con este grandulon" (59), le dice a una vaca. Y luego: "le dio de patadas [al becerro] cuando vio que mamaba de las cuatro tetas" (59-60). En este sentido, resulta que además de atentar contra el orden del relato en primer lugar y contra el orden espacial y social después, Esteban, erigiéndose en inocente justiciero, atenta contra la impunidad de aquellos a los que la ley no castiga, porque son precisamente sus enunciadores.

La inversión de la mirada

Así como Esteban se esconde hasta "hacerse perdedizo" cuando ve al patrón, para que éste no lo vea, del mismo modo, cuando llega con las vacas y encuentra la tranquera cerrada, se escabulle para que éstas - corporeización de Justo- no lo vean: "Me fui sin que me vieran" (59; el subrayado es mío). Es decir, que Esteban ve sin ser visto, lo cual implica que se ha producido en el texto una inversión de las jerarqufas sociales: el patrón resulta ser el personaje que no ve. No puede, por lo tanto, ordenar, en ningún sentido de la palabra: ni dar ordenes ni imponer orden. Porque ver es condición necesaria para ordenar. El texto mismo sienta este supuesto cuando Esteban, que sí ve, ordena efectivamente, en los dos sentidos mencionados: da la orden a la vaca desahijada de que mire al becerro "como si fuera a morir" (59) e impone orden al castigar al becerro incestuoso "cuando vio que mamaba de las cuatro tetas".

Por otro lado, la hermana de Justo, eternamente despierta, todo lo ve y lo sabe. Pero el incesto - el des-orden- se produce al amanecer, cuando ella no puede ver porque "se dormía como si se entregara a la muerte" (61). Mediante esta comparación queda establecida en el texto una absoluta equivalencia entre tres elementos: no ver $=$ dormir $=$ morir. La pérdida de la visión es la metáfora utilizada en otro lugar del texto para narrar la muerte de Justo: "Una nublazón negra le cubrio la mirada cuando quiso abrir los ojos [...] hasta la oscuridad total" (62). 
¿Será, entonces, que a través de la metonimia de la mirada, el texto esté contando la decadencia, la muerte de un sistema, de una moral, de una legalidad que se relativiza, en tanto que no puede ocultar su origen, ya que éste se torna visible a partir de su propio funcionamiento? Sin embargo, Esteban se quedo dormido en las piedras. Se dirigio a su casa llevando los ojos cerrados. Estas palabras establecerían una vinculación muy estrecha entre los dos personajes, Esteban y Justo. Vinculación que se explicita plenamente cuando Esteban dice: "Quizás los dos estábamos ciegos y no nos dimos cuenta de que nos matábamos uno al otro" (63; el subrayado es mío). "Nos matábamos uno al otro": la muerte de uno, el patrón, implicaba al mismo tiempo la muerte de Esteban, el peón. Es decir que la primitiva relación de causa-efecto aparece ahora invertida: ya no sólo es Esteban la supuesta causa de la muerte de Justo, sino que aquí parece sugerirse que la muerte de Justo es causa a su vez de la muerte de Esteban. Esta vinculación establecida entre los dos personajes no es otra cosa que la interdependencia económica entre explotado y explotador: "no volví a trabajar con él" (60), dice Esteban. "Ni yo ni nadie, porque ese mismo día se murio".

Parecería, entonces, que lo que se narra es la imposibilidad del explotado de salir de su condicion, dada su absoluta dependencia del amo para sobrevivir. El texto no narraría la liberación de los humildes a la muerte del opresor, sino una sumisión mucho mayor, la encarcelación y aun la muerte. La ecuación esperable, muerte del opresor = liberación del oprimido, ha sido reemplazada en el texto por muerte del opresor $=$ muerte del oprimido. Como si el texto presentara sólo dos posibilidades excluyentes: o bien la interdependencia economica de los dos personajes como condición de supervivencia, o bien la muerte. No existiría, aparentemente, una tercera posibilidad. Ninguna "luz" parece vislumbrarse: "Después vino la oscuridad" dice el narrador en el último párrafo. "Esa noche no encendieron las luces, de luto, pues Don Justo era el dueño de la luz" (63). 


\section{El lugar de la anunciación}

Pero un sentido opuesto, oculto durante todo el texto, surge hacia el final del cuento. En el velatorio de Justo las mujeres invocan a las almas del Purgatorio cantando "Salgan, salgan, salgan, ánimas de penas" (64). Sin embargo, esta invocación es susceptible de ser leída de otra manera, de acuerdo con una puntuación diferente: "salgan, salgan, salgan, animas, de penas". Según esta otra puntuación posible, la invocación a los muertos del Purgatorio se transforma en una exhortacion a los vivos de San Gabriel: ha llegado el momento de que las almas salgan de las penas, es decir, de abandonar las penurias. Aquí, oculta en esta breve frase, estaría la "luz" que hasta hace un momento no se vislumbraba. También ahora la descripción acompaña a este nuevo sentido: la oscuridad que predominaba unos renglones antes es sustituida por la mención del amanecer y del alba, última palabra del texto.

Desde esta nueva luz pueden resignificarse algunos elementos. La muerte de Esteban y Justo, muerte física de ambos personajes, puede entenderse ahora como muerte de dos clases sociales, como eliminación en el texto de las categorías de explotado y explotador.

El personaje protagonista adquiere además nuevas connotaciones. Esteban, el coronado, según la etimología de su propio nombre, es, en tanto víctima de la (in)justicia, coronado de espinas, como Cristo. $\mathrm{Y}$ es a la vez, en tanto víctima propiciatoria, coronado —elegido- por su muerte ritual. Muerte ritual que anuncia e inaugura un nuevo orden —el día que se inicia hacia el final del texto- sin explotador(es) ni explotado(s). El pueblo, San Gabriel, lleva el nombre del arcángel que anuncia a María el nacimiento de Jesús y constituye precisamente el espacio de la anunciación en el cuento. La piedra, instrumento del delito, es bajo esta perspectiva la piedra fundamental sobre la que se edificará un nuevo orden, una nueva legalidad. Y si Esteban sugiere a Cristo, esta vinculación se halla reforzada mediante la última frase 
pronunciada por el personaje: "Y en cuanto a mi alma, pues ahi también a Él se la encomiendo" (63).

El narrador, a su vez, es el Poncio Pilatos de la historia, el que jamás se pronuncia sobre la culpa o la inocencia, el que no toma partido, el que, habiendo comenzado a narrar en tiempo presente, toma distancia de los sucesos proyectando estratégicamente la historia hacia el pasado. Sus omisiones y silencios constituyen su principal estrategia discursiva para poner su voz al șervicio de la ley. Y si el silencio es cómplice de la ley, el habla, anagrama de alba -última palabra del texto- es precisamente su contrapartida, ya que es el discurso de Esteban la fundamental instancia cuestionadora de la ley en el relato.

Finalmente, la muerte de Esteban no es narrada. Queda fuera del texto, porque constituye precisamente su límite: el paso de este espacio social-textual a otro, diferente. De esto no hay escritura. El límite, muerte y resurrección a la vez, adquiere aquí un espesor, una textura: el silencio.

\section{BIBLIOGRAFIA CITADA}

Rulfo, Juan. "En la madrugada." El llano en llamas. 1953. Tezontle. México: FCE, 1980. 57-64. 